\title{
INTERDISCIPLINARY INTEGRATION FROM THE DEPTH OF DISCIPLINES IMPROVES LEARNING
}

\author{
Mammad Kazimov \\ Leading researcher of the Institute of Education of Republic of \\ Azerbaijan, $\mathrm{PhD}$ in pedagogy, associate professor \\ E-mail: memmedkazim@mail.ru \\ https://orcid.org/0000-0001-7020-4488
}

\begin{abstract}
The article deals with the integration of technology with other disciplines and simultaneously with the implementation of educational standards and curriculum requirements, the impact of integrative learning on the formation of logical thinking among students. The article also talks about an integrated approach to the study of interdisciplinary topics and on the ways of their deeper assimilation. The article focuses on the use of innovative techniques in the in-depth study of the subject, as well as advice and recommendations on the introduction of practical innovations and the benefits of integrative in secondary specialized educational institutions and examples are given on the subject from the works of various authors.
\end{abstract}

Keywords: integration, objects of natural history, creative thinking, modern training technologies, new approaches.

\section{DOI:}

To cite this article: Kazimov M. (2021). Interdisciplinary integration from the depth of disciplines improves learning. Journal of Preschool and Primary Education, Vol. 237, Issue IV, pp. 33-43

Article history: received - 03.11.2021; accepted - 16.11.2021. 


\title{
FONLORARASI İNTEQRASIYYA FONLORIN DORINDON ÖYRONILMOSINI TOKMILLOŞDIIRIR
}

\author{
Məmməd Kazımov \\ Azərbaycan Respublikası Təhsil İnstitutunun aparıcı elmi işçisi, \\ pedaqogika üzrə fəlsəfə doktoru, dosent \\ E-mail: memmedkazim@mail.ru \\ https://orcid.org/0000-0001-7020-4488
}

\begin{abstract}
Annotasiya. Məqalədə fənlərarası əlaqələrdən istifadə etmək, fənlərin dərindən öyrənilməsinə istiqamət verməklə yanaş1, öyrənmə mühitinin təkmilləşdirilməsindən də söhbət gedir. Eyni zamanda, fənlərarası inteqrasiya şagirdlərdə öyrənmə qabiliyyətinin formalaşmasına kömək edir, onlarda fənlərin öyrənilməsinə kompleks yanaşmaya, məntiqi təfəkkürün inkişafına istiqamət verir. Bu zaman fənnin dərindən öyrənilməsi məqsədi ilə innovativ metodlardan istifadə ön plana çəkilir, fənnin öyrənilməsində təcrübənin tətbiq olunması vacib şərt kimi qiymətləndirilir. Məqalədə fənlərin dərindən öyrənilməsində inteqrasiyadan istifadənin üstünlükləri də xüsusi qeyd edilir və müxtəlif müəlliflərin bu mövzuya aid əsərlərindən sitatlar gətirilir.
\end{abstract}

Açar sözlər: inteqrasiya, təbiət fənləri, yaradıcı təfəkkür, müasir təlim texnologiyaları, dərindən öyrənmə, müasir yanaşmalar.

\section{DOI:}

Məqaləyə istinad: Kazımov M. (2021). Fənlərarası inteqrasiya fənlərin dərindən öyrənilməsini təkmilləşdirir. «Məktəbəqədər və ibtidai təhsil», № 4 (237), səh. 33-43

Məqalə tarixçəsi: göndərilib - 03.11.2021; qəbul edilib - 16.11.2021. 


\title{
МЕЖПРЕДМЕТНАЯ ИНТЕГРАЦИЯ СОВЕРШЕНСТВУЕТ УГЛУБЛЕННОЕ ИЗУЧЕНИЕ ПРЕДМЕТА
}

\author{
Мамед Кязимов \\ Доктор философии по педагогике, доцент, ведущий научный \\ сотрудник Института Образования Азербайджанской Республики \\ E-mail: memmedkazim@mail.ru \\ https://orcid.org/0000-0001-7020-4488
}

\begin{abstract}
Аннотация. В статье рассказывается об интеграции технологии с другими предметами, а также о внедрении образовательных стандартов и требований куррикулума, о влиянии интегративного обучения на формирование у студентов логического мышления, о комплексном подходе в изучении междисциплинарных тем и о путях более глубокого их усвоения. Автор статьи выдвигает на первый план использование инновационных методов в углубленном изучении предмета, а также дает рекомендации по внедрению практических заданий. В статье отмечаются преимущества интегративного обучения технологии в средних специальных образовательных заведениях, приводится примеры касающиеся темы от произведений разных авторов.
\end{abstract}

Ключевые слова: современные технологии, творческое мышление, предметы природоведения, интеграция, продукты питания, современные подходы.

\section{DOI:}

Ссылка на статью: Кязимов М. (2021). Межпредметная интеграция совершенствует углубленное изучение предмета. «Дошкольное и началное оброзование», № 4 (237), стр. 33-43

История статьи: поступила - 03.11.2021; принято - 16.11.2021. 


\section{Введение / Indroduction}

Основными задачами, стоящими перед средне-специальными учебными заведениями, являются внедрение современных технологий обучения, повышение качества обучения за счет широкого использования интегративных методов при подготовке специалистов и соблюдение принципа направленности на результат.

Для воплощения в учебном процессе всего вышесказанного следует обратить особое внимание на выполнение требований образовательных стандартов. Выполнение этих образовательных требований оказывает положительное влияние на развитие направленности на результат образования, создание основы для формирования личности, для подготовки высококвалифицированных специалистов в своей профессии и выдвигает на первый план важность комплексного изучения предметов [Аббасов А. Н., 2009].

Внедрение новых методов обучения студентов интегративному изучению дисциплин в средних специальных учебных заведениях будет вносить позитивный вклад в подготовку специалистов. Интегративное обучение играет главную роль в развитии логического мышления студентов при изучении и усвоении ими аналогичных тем из разных дисциплин. Междисциплинарные связи и междисциплинарная интеграция способствует также экономии времени. За счет этого времени возможно более углубленно и качественно изучить и усвоить предмет, установить позитивный взаимный диалог с преподавателем. В результате, созидание интеграции в процессе изучения тем способствует формированию какой-либо области, созиданию свободного научного обмена и закладывает основы для разработки новой концепции. [Рустамов Ф.А., 2007; Кязимов М.С., 2016; Алиев П. Б., 2015].

\section{Основная часть / Main part}

Основной целью интегративного изучения технологии является подготовка студентов в новых социально-экономических условиях к самостоятельной жизни, усвоение ими умений и навыков в профессии. Для того, чтобы реализовать эту идею в жизнь, будущие учителя- предметники должны хорошо усвоить этот предмет, а также способствовать усвоению теоретических задач и соблюдению четких методик и правил преподавания технологии в школах. Создание в преподавании предмета технологии интегративных связей с другими предметами определяет направления в комплексном изучении данного предмета «Изучая предмета технологии, каждый студент должен знать:

- уметь использовать современные методы обучения при изучении технологических процессов; 
- уметь использовать усвоенные теоретические знания на практике;

- быть знаком с научной основой современного производства;

- уметь обращаться с наиболее распространенными современными оборудованиями и инструментами;

- усвоить практические навыки в процессе технологии обработки материалов и приготовлении продуктов питания;

- развивать творческое мышление при изучении технологических процессов, расширять эстетическое мировоззрение;

- уметь организовать социально полезный и продуктивный труд учеников на школьных и внешкольных занятиях с учетом их индивидуальных особенностей и познавательных способностей» [Посталюк Н. Ю., 2014].

Если в процессе преподавания технологии создать интегративные связи с другими дисциплинами, то это будет способствовать более эффективному усвоению предмета. Эти дисциплины следующие: химия, физика, биология, география, черчение, математика и электротехника. Знание химии необходимо при изготовлении деталей и частей изделий из древесины и металла и покрытии их специальными химическими составами.

В процессе практических занятий по обработке древесных материалов преподаватель напоминает студенту о важности нанесения защитного покрытия в процессе обработки. Защитное покрытие состоит из красок и лакировочных средств. При этом преподаватель дает задание изучить химический состав и особенности этих материалов, возможные реакции их с другими веществами, вредное влияние их на человеческий организм. При нанесении на поверхность деталей специальных консервантов, таких, как лаки, синтетические и натуральные красители, наполнители, а также других защитных покрытий. Учитель должен проинформировать студентов о химическом составе и строении этих веществ. Здесь возможны химические реакции с другими веществами, студенты должны знать химические свойства, позволяющие защитить поверхность металла или дерева от истирания и коррозии, выполнять индивидуальные задания. Или преподаватель при изготовлении деталей предлагает студентам подготовить чертежи изготовляемых деталей. При этом студенты должны изучить также и черчение, чтобы уметь разбираться в схемах и чертежах, то есть происходит интеграция технологии с черчением. Таким же образом, при изучении соответствующих тем возможна организация интегративного изучения технологии с химией, биологией, географией, электротехникой и др. «При ответах на вопросы студенты в соответствии с задачами должны быть в состоянии использовать различные источники и соблюдать нижеследующее:

- в процессе самостоятельной работы студенты должны иметь возмож- 


\section{http://ppe-journal.edu.az}

ность свободного выбора предмета и интеграции тем в соответствии с программой обучения;

- должны быть ознакомлены с условиями, в которых они будут самостоятельно выполнять индивидуальные задания;

- должны провести презентацию по самостоятельно выполненному индивидуальному заданию» [Кошелев С.С., 2013].

При изучении темы «Технологии производства продуктов питания», входящий в состав специальности технология, необходимо дать студентам информацию о биологических процессах, происходящих при обработке пищевых продуктов; о бактериях, вызывающих ферментацию и брожение; о съедобных и несъедобных грибах, об их происхождении; о скоропортящихся говяжьем и курином мясе, рыбе и особенностях профилактики этих процессов.

С целью изучения создания междисциплинарной интеграции учитель дает каждому студенту индивидуальное задание. На основании этого задания группа студентов (3 - 4 человека) проводят лабораторный анализ с целью профилактики быстрой порчи продуктов питания; другие занимаются созданием рецептов для приготовления пищи; третьи занимаются обработкой пищевых продуктов (мясо, рыба и т.д.); четвертые занимаются непосредственно приготовлением пищи.

Таким образом, на основании полученных заданий студенты не только изучают состав продуктов, учатся обрабатывать пищевые продукты и готовить пищу, но и изучают процессы ферментации и брожения, тем самым определяя особенности интегративных связей. О полученных результатах они готовят индивидуальные отчеты и общую презентацию.

«При выполнении заданий студенты должны выполнять нижеследующее:

- при выборе междисциплинарных тем для интеграции необходимо учитывать их особенности соответствия;

- во время проведения практики группы разделяются на подгруппы и проводят презентацию о полученных результатах и интегративных возможностях;

- индивидуальные и групповые задания должны выполняться под руководством учителя или научного руководителя (тьютора)» [Пугач В.Е., 2016].

Почти все специальные предметы, составляющие предмет технологии, связаны с физикой, электротехникой и преподаются в интегративном виде, поскольку технология обработки дерева и металла, работа с тканью и технология ткани, технология обработки в пищевой промышленности требует 
использования технологического электрооборудования и оборудования по горячей обработке.

Для работы на этом оборудовании необходимо:

-знать принципы работы электродвигателей и их совместной работы, правила обращения с ними, способы запуска и остановки двигателя;

-дать студентам информацию о кинематических схемах и правилах безопасности при работе с оборудованием.

«При работе на оборудовании необходимо использовать специальную защитную одежду, а также определить, на какие области знаний следует обратить особое внимание» [Алиев П. Б., 2015; Кязимов М.С., 2016; Лиферон А. П., 1997].

В процессе преподавания технологии деревообработки, входящей в состав технологии, на первый план выходит изучение древесных показателей. При выборе лесных материалов для деревообработки необходимо обратить особое внимание на изучение и использование информации об используемых материалах. Должны быть изучены тип древесины, механические свойства, химический состав, плотность и другие характеристики выбранного материала. Для этого необходимо уделять особое внимание интеграции с географией в процессе преподавания раздела «Технология деревообработки».

При создании деталей на основании заданных схем студенты должны быть ознакомлены со всеми техническими показателями используемой древесины и иметь навыки по ее правильному подбору. Только усвоив все вышесказанное, студенты смогут сделать самостоятельный выбор при изготовлении деталей.

На процесс обучения и изучения технологии, оказывающим положительное влияние фактором является организация интегративного обучения данного предмета с черчением. При изготовлении на основании задания той или иной детали студенты должны изучить схему детали, уметь на основании схемы определять размеры детали, знать кинематические схемы оборудования, используемого при изготовлении деталей. Поэтому очень важно изучение черчения и усвоение студентами определенных знаний по этому предмету. При изучении черчения студентам необходимо усвоить знания о линиях вообще, линиях соединения, уметь читать чертежи, работать с масштабами и т.п.

Создание у студентов полного представления о черчении возможно при изучении технологии тканей и работе с ними. При этом студенты учатся создавать шаблоны и приобретают навыки чтения схем.

«Создание в процессе преподавания технологии интегративных связей 


\section{http://ppe-journal.edu.az}

с вышеуказанными дисциплинами создает условия для более углубленного изучения предмета и определяет основные направления этого предмета [Алиев П. Б., 2015; Посталюк Н. Ю., 2014; Коротков Э. М., 2006].

Прежде чем проводить педагогический эксперимент, необходимо провести диагностику знаний студента о технологии, и ее интегративной связи с другими дисциплинами. Диагностику знаний студента о технологии, и ее интегративной связи с другими дисциплинами можно изучить с помощью нескольких методов. Несколько методик для подобной диагностики было предложено Научно-Исследовательским Институтом Стратегий Развития Образования при Российской Академии Образования. При преподавании технологии мы предлагаем использовать следующие методики:

1-ая методика - диагностика самооценки при интегративном преподавании технологии;

2-ая методика - диагностика отношений к созданию междисциплинарных связей;

3-я методика - диагностика отношений к созданию учебных мастерских и проведению практических занятий;

4-ая методика - диагностика дисциплин, наиболее часто интегрируемых в процессе связного преподавания технологии и определение используемых материалов. Педагог информирует студентов о каждой методике, составляет опросник из 10 вопросов отдельно по каждой методике и предлагает их. Вопросы должны полностью охватывать темы, соответствующие каждой методике. Примерные вопросы таковы:

1. Насколько важна интеграция в процессе изучения технологии?

2. Интеграции каких дисциплин отдаете предпочтение?

3. Каковы преимущества интеграции с естественными дисциплинами в процессе обработки?

Ответы студентов анализируются, оцениваются и полученные результаты даются в виде таблицы.

Еще один из экспериментов, проводимых со студентами II-III курсов, состоял из вопросов, касающихся уровня осведомленности их об интегративном преподавании технологии. В данном эксперименте участвовало несколько студентов. Уровень знаний оценивался как «знает», «слабо осведомлен», «не знает». Результаты статистически обрабатывались в процентном отношении и заносились в таблицу. На основании этого эксперимента можно определить степень усвоения технологии в процессе ее интегративного преподавания

Кандидат педагогических наук, доцент С-Пб. ГУ В. Е. Пугач в своей статье «Проблемы межпредметной интеграции в средней школе» пишет: 
Межпредметная интеграция совершенствует углубленное изучение предмета

«Мы допускаем конвергенцию подходов на современном этапе, хотя и понимаем всю ее сложность. А педагогам нужно стремиться к реализации интеграции на практике, постепенно «вживляя» интегрированный подход в образовательный процесс» [Пугач В.Е., 2016]. Доктор педагогических наук, академик

Г. Н. Филонов пишет: «Интегрированные гуманитарные знания существенно меняют понимание целевых установок, предмета, задач, воспитательной деятельности, ожидаемых результатов» [Посталюк Н. Ю., 2014]. Действительный член Академии Педагогики и Социальных Наук России, проф. А. Н. Аббасов пишет: «В настоящее время дифференциация наук указывает на необходимость интегрированного их изучения» [Аббасов А. Н., 2009].

Профессор И.Г.Джебраилов пишет: «Организация интеграции и интегративный процесс преподавания являются основным средством для углубленного изучения предметов».

Мы считаем целесообразным осуществление нижеследующего в процессе преподавания и обучения данному предмету:

- целесообразно кроме занятий в аудитории давать студентам задания на дом;

- темы обучающих заданий, самостоятельных работ и индивидуальных презентаций должны соответствовать программным темам;

- самостоятельные работы и индивидуальные задания должны выполняться под руководством научного руководителя;

- презентации курсовых и проверочных работ должны проводиться в присутствии комиссии;

-тестовые вопросы или вопросы по письменным семестровым и выпускным экзаменам должны быть обнародованы за месяц до экзаменов;

- очень важно участие студентов в семинарах, кружках и других мероприятиях, организуемых колледжем. 


\section{Заключение / Conclusion}

Теме интегративного обучения посвящено много исследовательских работ. Например, американский исследователь Джон Дьюи считает, что при поиске путей из жизни в науку и, наоборот, возможно интегративное обучение различным дисциплинам. Таким образом, с помощью дидактических принципов можно установить междисциплинарную коммуникацию и обеспечить связь предмета с жизнью. Интеграция также может играть важную роль в вопросах, которые решаются с участием двух или более дисциплин. Такая интегрированная система обучения также была разработана в области других дисциплин.

Актуальность статьи. В ходе изучения смежных дисциплин и интегративного обучения улучшается усвоение учащимися выбранной темы, совершенствуются их аналитические способности и повышается способность устанавливать связи при изучении соответствующих дисциплин.

Научная новизна статьи заключается в установлении междисциплинарных учебных связей с использованием интегрированных методов обучения при изучении естественных наук. С этой целью при преподавании технологии создание междисциплинарных методов преподавания, связанных с химией, физикой и географией, поможет учащимся лучше понять и глубже изучить предмет.

Практическая значимость исследования. В статье доказано, что преподавание естественных наук в связи с предметом специализации, а также с использованием всех видов междисциплинарных подходов, дает возможность использования полученных результатов при преподавании естественных наук в средних специальных учебных заведениях и гимназиях. 


\section{Список использованной литературы / References}

1. Аббасов А. Н. (2009). Педагогика. (учебник для средних специальных учебных заведений) / А. Н. Аббасов. Баку, «Мутарджим», 348 с.

2. Ахундов С. А. (2009). Пути созидания связи между предметами / S. А. Ахундов. Баку, «Мутарджим», 216 с.

3. «Государственное Стратегия» по развитии образования Азербайджанской Республики. «Азербайджан», (2013), 25 октябрь, c.1.

4. Алиев П. Б., (2015). Принципы и содержания управления образованием. Баку: //«Научные труды»// ИПОАР, № 2, с. 62-65.

5. Кязимов М.С. (2016). Роль межпредметных связей по повышению качества образования Баку: // «Азербайджанская школа»//, № 2, с. 57-63.

6. Рустамов Ф. А. (2007). Педагогика высшей школы. (учебник) / Ф.А. Рустамов., Т. Й. Дадашова. Баку, «Нурлан», 568 с.

7. Кошелев С.С. (2013). Современные методы обучения / С. С. Кошелев - Москва: «Тетра Системс», 218 с.

8. Коротков Э. М. (2006). Управление качеством образования. (учебник, пособие для педагогических вузов). / Э.М. Коротков - Москва: Академический проект: «Мир», 320 с.

9. Лиферон А.П. (1997). Интеграция мирового образования - реальность третьего тысячелетия / А.П. Лиферон - Москва: «Педагогика»,-231 с.

10. Посталюк Н. Ю. (2014). Интеграционные процессы в Российской системе профессионального образования // Москва: «Интеграция образования», № 4(77), с. 86-89.

11. Пугач В.Е. (2016). Проблемы межпредметной интеграции в средней школе // Москва: «Педагогика», № 6, с. 41- 46.

12. Пузанкова Е. Н., Бочкова Н.В. Современная педагогическая интеграция, ее характеристики. [Электронный ресурс]. Москва, URL: http www / jeducation. ru > 1_2009-9.html. 